\title{
Assessment of Energy Use on Urban Kathmandu from Energy Cultures Framework in Gender Perspective
}

\author{
Bindu Shrestha ${ }^{1, *}$, Sushil B. Bajracharya ${ }^{1}$, Sudarshan R. Tiwari ${ }^{1}$ \\ ${ }^{1}$ Department of Architecture \& Urban Planning, Pulchowk Campus, Institute of Engineering, Tribhuvan University, \\ Nepal \\ Corresponding email: shresthabindu@gmail.com
}

\begin{abstract}
:
The urban household has a high potential for energy saving to reduce carbon emission; however, it has been scant attention in Nepalese energy policy. Though sustainable development has set 2030 goals to achieve high impact on energy with a focus on women' role, Nepal is still lagged for effective participating women properly in the energy sector. Urban women have a triple role with significant responsibility for household chores, and efficient cooking is one of pertinent attitudes to reduce energy in Kathmandu. Household energy is highly influenced by human behavior, energy culture, and practices, more significant role for shifting technology, that has less consideration in the policy. This paper aims to assess the energy practices identifying trade-offs of an energy transition to cleaner technology from the questionnaire survey, observation, interviews, and quantitative analysis in terms of a gender perspective. The analysis is based on energy cultures framework in gender perspective with primary attributes of cognitive norms, energy practices, and material culture to understand urban Kathmandu neighborhood. The field study showed that urban households are suffered from energy inaccessibility, inequality, and insecurity resulting in fuel stacking, socio-economic disparity, and environmental impacts. In conclusion, the energy-saving and reduced carbon emissions can be solved through prioritizing women's role as a change of agent with active participation, incentives, two-way communication, and awareness to improve the situation.
\end{abstract}

Keywords: Sustainability, Energy Efficiency, Energy Consumption, Energy Cultures, Gender Lens

\section{Introduction}

The move towards a low-carbon economy is one of the core elements to achieve energy efficiency [1]. The energy transition world has a challenge of societal change for sustainable energy and equitable future. The sustainable energy cultures lead to investigations of the social world that link outcomes to cultural formations, and identification of opportunities for energy efficiency [2]. Recognizing the importance of energy efficiency, Nepal has set 2030 goals to achieve sustainability but placing modern energy as a separate goal results the piecemeal development lacking a gender lens to understand the social world. However, Nepal represents modest energy consumed country in the world, the energy intensity is about four-times higher than the world average, and it is the highest in the region due to inefficiencies in energy consumption [3]. The lack of energy efficiency is one of critical component driving vulnerability to energy poverty because of the potential disproportionate high loss of useful energy in households [4]. Whereas there are lots of discourses on energy efficiency as it reduces energy or not. Despite the dilemmas, it has been increased evidence of energy poverty elimination and broader benefits on the economic, social, and environmental domain, for instance, energy savings and reduced GHG emissions are evident. Several studies conclude that energy efficiency has positive impacts on health, well-being, and improved living comfort. Furthermore, the International Energy Agency has concluded that a big revolution step in the attitudes to energy efficiency and consumer purchases by hundreds of millions of people worldwide is essential [5] to achieve sustainability.

Households are major production and consumption units contributing to national economies. In Nepal, residential is the largest sector of energy consumption contributing $87 \%$, and cooking consumes $61 \%$ of the total energy of household [6]. The energy-saving potential in the residential sector is enormous through the user's behavior. Urban women have, directly and indirectly, a responsibility for the household chores even they are working outside of the home in Nepal. It shows that women have a more significant responsibility to save energy. Moreover, the country has implemented energy efficiency measures for more than a decade on a different scale at different levels; still, improvement is negligible; it fails to address the social issues and the needs of the community in sex-disaggregated data to provide proper 
input on the policy development. In the urban context, women are still major key drivers in household energy, and it has been neglected in the policy framework.

The traditional setting of urban Kathmandu is assumed as a low energy-intensive society, but modernization has changed the urban lifestyle with excessive energy demand. Even though the urbanization is one of driving factor in changing energy practice; the societal norms, values, and energy culture of the city have equal roles in transformation. As a result, the city as capital has a burden of solving the issue of sustainability from energy transition to cleaner energy. However, the sustainable development has emphasized on the energy accessibility, affordability, security, and cleaner technology (goal 7) and gender equality (goal 5), Nepal is still lagged to achieve a combined effect of energy and gender in the urban context. Some energy experts emphasized that the reason for the slow transition to clean energy services is a result of failure to address gender dimensions in energy poverty [7]. Despite growing recognition of the inherent unsustainability and injustice of fossil fuel civilization, it has been persisting issue as an inability to reduce fossil fuel [8]. Energy justice and sustainability expect to perceive a more equitable distribution of political, economic power; and greater social and neighborhood control of energy [9]. Besides, gender-responsive energy framework can enhance the differentiated sociocultural experiences, needs, and priorities of women and men to overcome gender biases and integrate them to promote gender equality and empowerment [10]. The previous studies have lack of proper gender lens to analyze household behavior to understand the values, emotions, and needs in a gender perspective. This paper attempts to highlight the condition of sustainability and injustice in the energy consumption pattern understanding the gap of gender lens. The purpose of this paper is to present a conceptual framework to understand the factors that influence the energy decisions of women and men in the context of Kathmandu.

\section{Literature Review}

The data of the energy use in different sectors have been compelled to investigate in the formulation of energy policy whereas most energy analysts ignore to link between energy and women and argue that energy is there for all to use. 'What difference does it make who uses it?' one could also argue that education is there for anyone who wants it or food for anyone who wants to eat. However, gender shows marked differences highlighting inequality in time, needs, and decision-making in society.
Thus, the response 'energy is for anyone who wants to use it' evades specific underlying issues especially in emerging nations and perhaps even in the industrial countries the genders are not an equal footing [11]. The recognition of this factor emphasized on International Women's year in 1975, extended as women's decade. Although, the earth summit, agreed that sustainable development is a balance of economic growth, social equity and environment protection [12], even after four decades, inequality persists in large extent especially in emerging countries. It suggests a contextual understanding of energy use pattern, accessibility, and culture from a gender perspective.

However, energy access is recognized as human rights achieving energy justice; the energy framework of most countries does not include gender references [10]. Whereas energy accessibility of resources and technologies across the world are intertwined with gender roles in the social ground and power relations [13]. The power relationship is started from the household entity and division of works that is embedded within societal, cultural, and institutional energy services [7] that impacts on decision-making. Bedlin [14] perceives the structural differences in society is a result of gender-related differences that are deeply rooted in institutions and norms, accepted by individuals. In a broader perspective, Cecelski [15] expresses the gender-sensitive strategy claiming contextual gender and energy analysis for the transformation beyond the welfare needs. Women are not to be treated as a homogenous category. However, a bargaining model of the household is assumed as a unitary model with identical interests; gender relations and gender roles need to be analyzed beyond the household level [16]. The intra-household relationship study identifies the women have a potential of bargaining capacity to involve in decision-making and supply chain programs promoting cleaner energy and technologies as a change of agent in the society [7].

The importance of energy saving has been evolved since 1970, when the oil crisis triggered the situation. The numerous studies of energy consumption behaviors in different disciplinary perspectives are introduced to understand the influencing factors in energy decision of consumers and their impact on the adoption of more efficient energy practices in the neighborhood. These perspectives include microeconomics; technology adaption models; social and environmental psychology, organizational behavior, and socio-technical systems [17, 18]. The numerous integrating models have been devised to seek drivers of behavior and their interlinked 
relationship. The early example was Dholakia et al.'s [19] 'macro-micro model of energy consumption' which was motivated by an interest of individual behavior defining two layers of choices in energy use. Similarly, Van Raaij and Verhallen [20] structured the 'behavior model of energy use' highlighting the interrelationship between influences on energy use and behavior. However, those models were helpful to understand the behavior; it did not attempt the integrated concept in gender perspective and cultural groups. Whereas energy use behavior demands inter-disciplinary insights, and that was introduced by Lutzenhiser's [21]'cultural model'. Wilk [22] offered a 'multigenic' model with an additional dimension of gender relations, that was more refined by Keirstead's [23] 'actor-networked' theory for residential energy consumption, including the interaction between government policies and standards, market structure, and households. However, the energy is interdisciplinary and multi-layers agenda; the gender issues have been less emphasized in energy theory.

Energy is a social agenda evolved as the social movement [24] and shifting from fossil-fuel-dominated systems towards renewable-based energy has become a central focus worldwide [25]. Achieving transformation is hard to imagine without the participation and engagement of all members of society in the process of energy transition [26]. Moreover, the energy transition is linked to a broader perspective of expanding political democracy, where the reforms of the energy sector serving to re-inspire a politically-engaged citizenry who participate as the citizen before consumers [27]. It attempts to involve marginalized groups, women, men, and all communities [28] because the energy system is dynamically shaped by the larger social, cultural, and political contexts in which they are embedded.

Mumford [29] stated that 'Every society is characterized by the means it uses to convert energy into life and to convert life into those higher forms of energy that we call culture'. Mumford's proclamation of a link between energy and culture was grounded on the optimistic future of energy transition. While the transition is strongly linked with the culture of society. Culture can transform society beyond social learning through language evolution, material culture, and models of cultural dynamics within and between groups [30]. It reflects virtually every aspect of social life; an idea, product, or innovation that reinforces cultural norms [31]. Recognizing the taxonomies of culture dimensions as individualismcollectivism, masculinity-femininity, power distance, uncertainty avoidance, and long-term orientation are much researched and validated [32]. According to Hofstede [33], male dominating society as a patriarchal society means high power distance nature reflecting continued propagation of inequalities of power and wealth within the society. In most parts of South Asia, including Nepal, women usually have less power than men in household decisions; however, women have a triple role of reproductive, productive, and community.

Moreover, women often have unequal access to education, healthcare, limited opportunities to earn. Nepalese women are disadvantaged by a lack of awareness of opportunities and their legal rights. Their low social status is one of barrier towards policy progress [34].

\section{Methodology}

The research is designed as a case study, appropriate to the analytics of process tracing. The energy context of Nepal is in 'critical case' having strategic importance to address the lack of access and fossil-fuel-based energy systems [35]. Nepal is a critically low energy consumption per capita as well as its geopolitical situation as a landlocked country. Kathmandu, the capital and largest city of Nepal, has a population of 1,442,271 with a high density of 20,288 people per square kilometer [36]. The city is a hub of opportunities for jobs, education, and major business centers. Historically the city dates more than 2,000 years, rich in ethnicities and cultures, and famous as trade zone. The study includes three city core neighborhoods of Gophal, Jaisidewal, and Lagan households of 3,389 and population of 13,727 according to the census of 2011 (Figure 1). However, the study area is near the historical zone, it has been highly influenced from the proximity of vibrant economic business zones, and the area has been extremely transformed dramatically after the disaster, replaced with new houses and new immigrants. It has a direct impact on energy use in a crosscultural environment.

The data collection tool is a semi-structured closed questionnaire survey of household demographics, cooking technology choices, energy-intensive social activities, and energy efficiency concept in gender-disaggregated data. The questionnaire was administered to 250 households from January to April 2017, either to household heads or spouses, and especially women because they are responsible for cooking energy decisions. Additional unstructured interviews were done with local people. Microsoft Excel and Statistical Package for Social Sciences (SPSS) were used to analyze the data. Pearson correlation, cross-tabulation, frequency, and Chi-square test were used for univariate and bivariate correlation 
study, while multi-variable linear regression analysis was used to determine relationships between variables. Literature reviews and peer-reviewed articles supported the preliminary study.

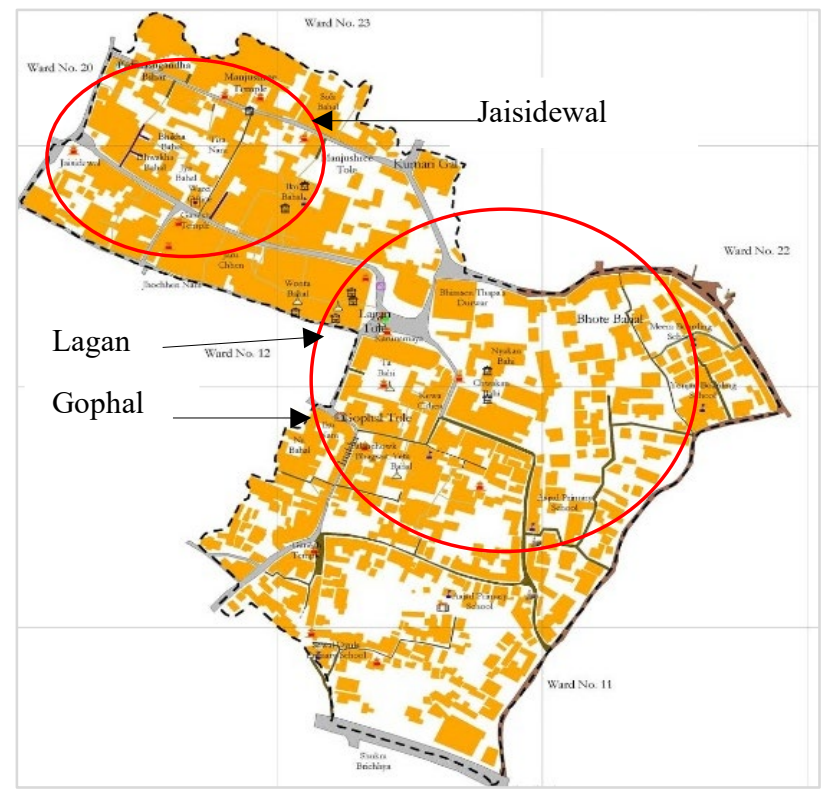

Figure 1: Study area of city core

Based on the literature of energy behavior, the energy cultures framework is used to understand the behavior, norms, and practices in a gender perspective. The energy culture model was elaborated by Stephenson et al. [2], and this study tried to perceive energy cultures model in gender lens. The envisaged framework is intended to have two fundamental propositions. The first is energy efficiency behavior with holistic cognitive norms, material culture, and energy practices on the context. The second is visualize the situation of women within and outside of the household in a gender perspective to define the gender differences of actual scenario in urban Kathmandu expatiating policy design.

\section{$4 \quad$ Result and Discussion}

The energy cultures framework looks at three core aspects of cognitive norms, material culture, and energy practices through the gender lens in terms of energy use and saving behavior of urban Kathmandu.

\subsection{Material Culture}

The distribution of the respondents is $40 \%$ male and $60 \%$ female. The mean family size of the respondents was 3.03. Regarding the ownership status of household dwellings, $65 \%$ were personally owned, while $35 \%$ were rental respondents.
The material culture of the study area reflects that a quarter of respondents had difficulty in accessing clean cooking fuel technology. Besides, the unhygienic kitchen and toilets are shared among the urban poor, resulting in vulnerability for women and children. The driving factors for such complex urban problems are the result of population growth and the influx of rural migrants in the form of stiff competition for resources, long journeys to work, congestion, waste management, lack of housing, energy, water which are inequitably distributed. The increasing rate of urbanization has far-reaching socioeconomic and environmental implications transforming energy consumption in a new behavioral pattern in terms of resources collection, distribution and uses [37] expanding a gap of inequality and social disparity.

\subsection{Energy Practices and Cognitive Norms}

The energy practices of Kathmandu had shaped by easiness, accessibility, and affordability. Liquefied Petroleum Gas (LPG) used by $86 \%$ dwellers as both primary and secondary cooking fuel. As shown in Figure $3 \& 4,40 \%$ of Nepalese depended on LPG for cooking allaround a year. $36 \%$ of Nepalese depended on wood fuel, especially rural residents. Few percentages of dwellers depended on kerosene (16\%) and other fuel types in mixed fuel in urban areas. However, both rental and house owners used a high percentage of LPG for daily cooking.

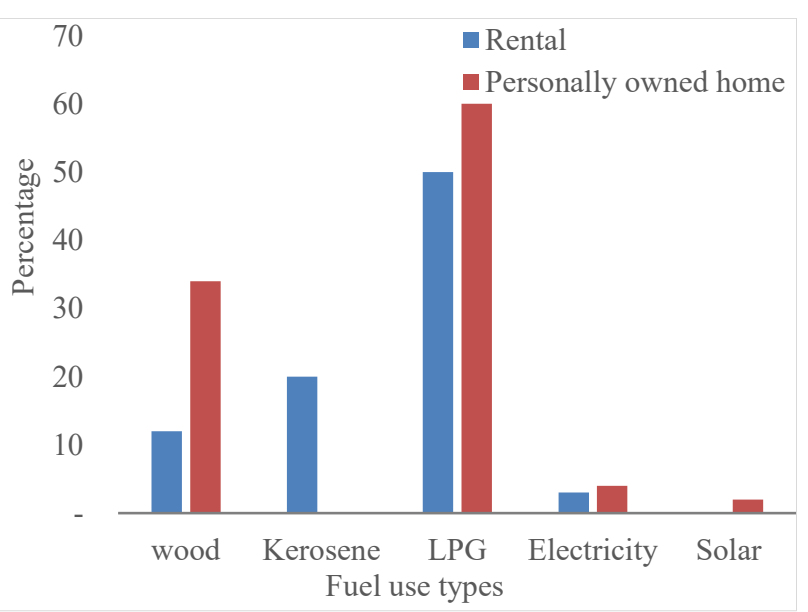

Figure 2: Fuel use depending on residence types

However, residents have fuel stacking culture because of frequent fuel crisis and price fluctuation in the market. The frequency analysis shows that LPG use was high comparatively other fuels (mean-0.9), doubled of wood utilization, and induction heater was used very low (mean -0.07 ) with a high standard deviation of 0.506 . Only $8.1 \%$ of people used electricity (Induction heater) for cooking. The energy practice of city was crafted by the frequent load-shedding which extends 12-18 hours in extreme 
conditions in a week. The study was conducted in three different income groups as low, middle- and high-income groups depending on their earning capacities based on national statistics. However, most of the studies show that income and education impact on the use of energyefficient technologies; the correlation between these two factors shows a contradictory result in this neighborhood. High-income and assets owned residents have been using clean fuel despite being illiterate. This result is more likely to the study of Huang in China. He found that Household assets capita increases by $10 \%$, probability of household choosing clean fuels increase 0.007 [38].

\subsubsection{Influential Factors on Energy Culture}

Energy consumption equations have been derived through multi-variable linear regression analysis for defining the role of influential factors in the cooking behavior in the urban household. The result shows that social activities (SA), change in homeownership status (HOS), house income (HI), level of education (Ed), ethnicity (Eth), gender $(G)$, occupation (OC) are influential factors on household fuel choice and energy-saving concept. Type of food, the quantity of food, easiness, fastness, and scarcity of primary fuel are additional drivers in fuel stacking culture, which are elaborated based on observation and interviews.

Equations (1), (2), and (3) represent the estimated fuel consumption impact from different factors using wood $(W)$, LPG $(L)$, and Induction (I) respectively.

$$
\begin{gathered}
W=0.380+0.037(S A)-0.076(H I)+0.099(O C)+ \\
0.289(E t h)-0.055(H O S)-0.103(E d)-0.131(G)
\end{gathered}
$$

However, the energy practice of using fuelwood as secondary cooking fuel, especially for social events in the neighborhood, it has an impact on carbon emission. The study area is predominated by Newar ethnic group, which has a historically driven energy culture of using solid and farmland waste. Moreover, the Newar ethnicity has a cooking practice of using wood for special food taste, for instance, haku-choyla (ethnic barbeque) and preparing home-brewed alcohol (Rakshi) for special events, which takes three-four hours per session using wood and particular types of utensils Figure 3.

The tradition has been slightly transforming due to the introduction of new energy type, for instance, LPG and electrical cooking; however, traditional women still follow the norms of cooking traditional food and drink in special events. The observation shows that ethnic activities occur more than twenty events, indoor and outdoor in a year. It causes tentatively 2000-3000-tonne carbon emission from studied neighborhoods while using fuelwood as a secondary fuel. Furthermore, fuelwood is used for winter as a dual purpose for cooking and heating rooms. Refer to equation (1) denotes that the city has a challenge of environmental pollution intertwining energy culture and cognitive norms of traditional beliefs.

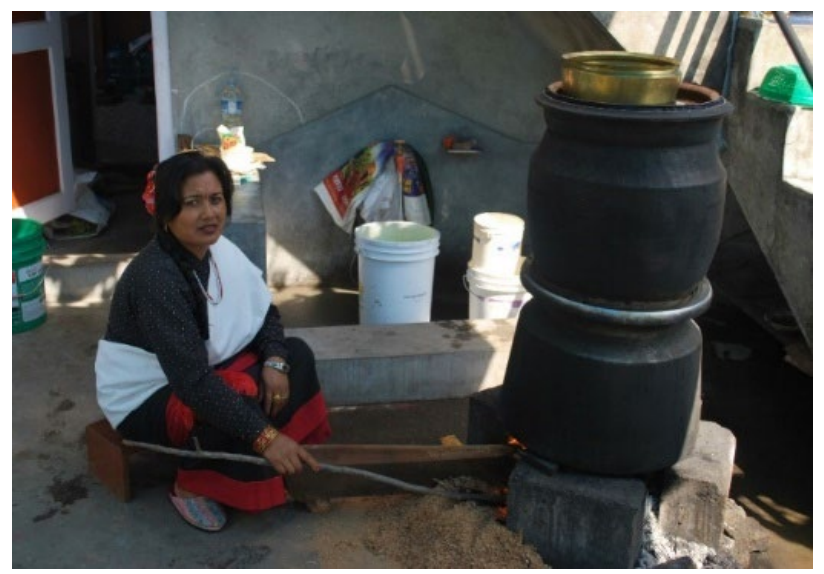

Figure 3: Traditional way of home-brewed alcohol

The fuelwood is the largest source of energy and occupies $70 \%$ in a fiscal year in Nepal. The polluted matter (PM2.5) is found in wood cooking counts from 10-100, having high impact on health implications [39]. In Nepal, almost 5000 people died from respiratory, lung cancer, and infection; one of reason is associated with kitchen cooking environment and indoor pollution.

$$
\begin{gathered}
L=0.156-0.037(S A)+0.056(H I)+0.001(O C)+ \\
0.046(E d)-0.091(H O S)+0.477(G)
\end{gathered}
$$

Refer to equation (2) shows that the consumption of LPG increases when the household income upgrades, occupation increment, and higher literacy rate occurs, successively by $0.056 \mathrm{Kg}, 0.001 \mathrm{Kg}$, and $0.046 \mathrm{Kg}$. The LPG consumption less used in social events especially by Newar group those who have to celebrate traditional cultures use LPG lesser by $0.037 \mathrm{Kg}$, and $0.091 \mathrm{Kg}$. LPG is largely influenced by the accessibility of households. The both rental and personally owned women prefer to use LPG as a first choice, because of easiness, but $20 \%$ of poor economic rental women follow fuel mix to manage their economy. Solar energy is rare for cooking, except $14 \%$ of respondents used solar energy only for lighting purposes.

Due to dependency culture, Nepal frequently suffers from the LPG crisis for more than a decade, and people pay three times more than the actual price for the same gas resulting corrupted market, which has ultimately created a big gap of socioeconomic disparity. However, the indoor kitchen pollution is much lesser (PM 2.5: 1.7-10) than wood cooking fuel, but still, it does not meet the requirement of the World Health Organization standards as it is considered as less clean fuel. 


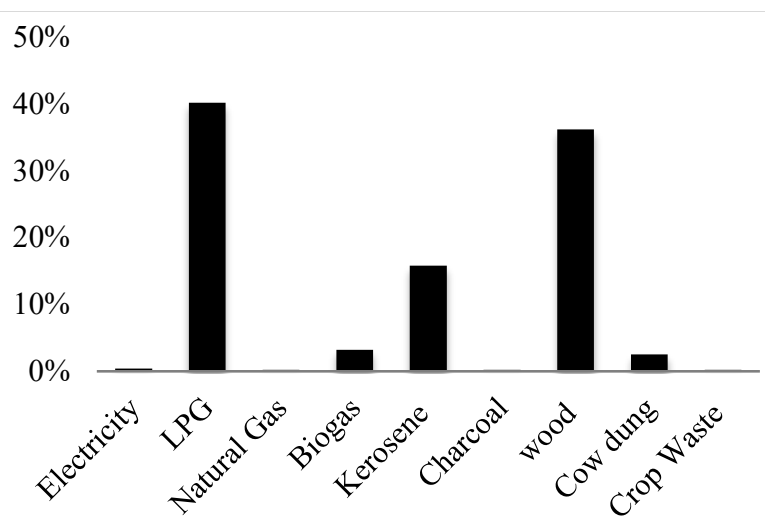

Figure 4: Fuel consumption pattern in Nepal

$$
I=0.111+0.004(S A)+0.044(H I)-0.122(O C)+
$$$$
0.49(E d)-0.187(E t h)-0.046(H O S)+0.202(G)
$$

Refer to equation (3) shows that use of electricity consumption for cooking increases when the house income, education, gender knowledge, and social activity are enlarged successively by $0.044 \mathrm{kwh}, 0.49 \mathrm{kwh}, 0.202$ $\mathrm{kwh}$, and $0.004 \mathrm{kwh}$. The material culture of using electricity as a cooking fuel is rare on social events due to requirements of special utensils that counts burden of additional cost however the US department study reveals that induction stove (84\%) has the highest energy efficiency compared to other fuels [40]. The result shows that the use of clean, green, and efficient technology for cooking is electricity that meets the WHO standards, though the residents could not depend on it because of energy insecurity and economic disparity. It suggests an understanding of proper technical knowledge, guidance for users, financial support, and women, men, and social needs for promoting the cleaner technology in policy level.

It revealed that high price, inaccessibility, insecurity are significant barriers to transform the transition to cleaner energy. For instance, $32 \%$ of people in an urban area has a scarcity of affordable cleaner technology due to direct and indirect high energy cost [40]. While the Nepal Electricity Authority has been improved the electricity management through the leakage and changing schedule system and providing continuous electricity access in the Kathmandu from 2017, it can be an opportunity for shifting towards modern and clean cooking fuel technology. Societal-technology leapfrogging is essential to achieve a global emission reduction of $80 \%$ and stabilizing climate change. Leapfrogging can only occur if the marginalized group can access relevant technologies [41].

During the interview with few women expressed their views on using electrical cooking (induction heater), say:
"Induction stove is good due to the digital cooking option. It is safe and no risk of gas leakage. In kitchen, wind from a window near LPG stove always has a problem but using induction, I can open the window and feel comfortable in cooking. However, my husband did not allow to use it because of a high electricity bill" (Female Respondents, age 50, 52).

The narratives showed that male paid the electricity bill so they might not eager to pay high amount and reluctant to use electrical cooking while women preferred to use due to safety and less burden to carry cylinder. LPG cooking kitchen needs to have air circulation for the safety factor but in urban kitchens have rarely found proper ventilation. In this consideration, women expressed few disadvantaged of LPG cooking, however, it is quick and easy for use. It indicates that lack of understanding and power relationship in energy decisions. However, the indicator exhibits a great achievement in reducing in gender gap in school education, women's equal access to economic resources, but it has limited progress in energy decision-making over the years.

\section{$5 \quad$ Energy Cultures from Gender Lens}

The study framework depicts three core influences on energy-related behaviors over which the individual or collective has some degree of control and differentiates from 'external influences.' The material culture consists of relevant technologies and other physical infrastructure. In examining the household cooking culture, their relevant material culture includes low traditional fuel stove, excessive LPG stove, and low induction stove uses and high demand for storing spaces. Practices include both regular and irregular actions, and cooking include cooking time, styles, varieties, and food amount. Norms are personal and social expectations about how life should be lived, including expectations about safety, secured, quickness, easiness, and affordability aspirations.

On the study of human behavior by environmental psychologists, behavioral economists, and other social scientists examined the theory of change to understand the action on energy consumption. The theory of planned behavior suggests that people are influenced by a way of thinking, action on their happiness, influential people and group (such as fashion), and easiness or comfort. The study suggests that programs should be targeted on attitudes, perceived social norms, may successfully change behavior. However, Sussman [42] emphasized that psychology-based behavior change programs are only part of the solution; they work best when combined with incentives, policies, and laws. The energy culture 
framework aims for change at the level of a social group rather than an individual [43]. The study shows that interventions of the behavioral approaches can be as or even more effective at achieving energy-efficient behavior. In contrast to the traditional behavioral perspectives, it considers women's and men's decisionmaking, including social cues, self-image, status quo, local values, and identities. To achieve energy transition towards cleaner technology in the city, it needs to dig deeper in energy-saving system, their attitudes and behavior in the household to engage in multiple mechanisms; that may be invisible, intangible.

In Kathmandu, fuel stacking is one of barrier in energy transition, which is a core influencing factor on material culture. It has a stronger role to interact with available technologies, household income, and energy regulation, which is promoted from cognitive norms, for instance, education, upbringing, and demographics of a neighborhood. An appropriate energy regulation system, for instance, reliable and low energy price, should be mandatory in the government policy culture. Moreover, this approach will be strengthened through social norms. The implementation can be motivated through the right incentives in the form of financial, status-based awards, and reduce the upfront real or perceived costs of the action. Such incentives are effective in triggering a quick turnover of old appliances to new energy star cooking appliances [43]. The approach is based on inclusiveness, active participation, and communication, so it will be helpful to resolve the Kathmandu's challenge of socioeconomic disparity. Communication as active twoway participation is the best way to aware and educate people in a proper way for right information based on the science behind energy efficiency and to shift towards cleaner technology.

The study suggests using less and cleaning energy as a culture rather than a mandatory obligation. Each everybody's voice is important, so encourage participants to use cleaner technologies rather than feedback might work well. It suggests a tool of commitment based on cognitive norms with science-based energy saving culture, social aspirations, and environmental concern as a stronger role to resolve the issues regarding inefficient and unsafe cooking. Spoken, written, and public statements reinforce new identities and self-image, significantly altering behavior. Moreover, energy education should be included in the nation's curriculum at least up to the secondary school level. Awareness program should be included for the female in each household to encourage an idea of sustainable energy behavior because women spend maximum hours of a day on in the kitchen and household chores in Nepal. When women have access to and control over energy resources and can participate in decision making, they can be vital drivers towards effective policy change and implementation as 'agents of change.'

\section{Conclusions}

The household energy consumption pattern reflects that with the desired energy transition in Kathmandu runs along dual parallel processes: a transition from low-access to high access to modern energy and a transition from fossil-fuel-based energy to renewable energy. The government seems passive to achieve a clean and healthy environment; despite Nepal has a vision of doubling the renewable energy in household and neighborhood. The government needs innovative, inclusive, and incentive policy to motivate urban household in focus on women's status to enhance cleaner technology. Understanding gender preferences and dynamics can support the development of renewable energy policies and failing to involve them is a missed opportunity for ensuring energy access with an environmental benefit. Three decades' experience in various countries reinforces that energy efficiency programs can influence on behavior if they are carefully designed. This gendered energy cultures framework is significant to understand behavior pattern for crafting effective intervention and incentives empowering women as the change of agent.

\section{Acknowledgments}

The authors are thankful to the RETRUD-18, Institute of Engineering, providing an opportunity for presentation and publication of this study and highly appreciated to Dr. Hom. B. Rijal, Tokyo City University, faculty of environmental studies, Japan, for reviewing this paper.

\section{References}

[1] UNCCC, "Adoption of the," United Nations, 2015.

[2] J. Stephenson, "Sustainability cultures and energy research: An actor-centered interpretation of cultural theory," Energy Research \& Social Science: 44, pp. 242-249, 2018

[3] ADB, "Nepal Energy Sector Assessment, Strategy, and Road Map," Asian Development Bank, Manila, Philippines, 2017.

[4] S. Ugarte, B. V. D. Ree, M. Voogt, W. Eichhammer, J. A. Ordonez, M. Reuter, B. Schlomann, P. Lloret and R. Villafafila, "Energy efficiency for low-income households," Europian Union (European Paliament's 
Commitee on Industry, Research, and Energy (ITRE), 2016.

[5] IEA, "World Energy Outlook," International Energy Agency, France, 2008.

[6] AEPC and WBCD, Kathmandu, 2011.

[7] S. Pachauri and N. D. Rao, "Gender impacts and determinants of energy poverty: are we asking the right questions?," Environment and Sustainability, pp. 205$215,2013$.

[8] N. Healy and J. Barry, " Politicizing energy justice and energy system transitions: fossil fuel divestment and a just transition," Energy Policy 108, pp. 451-459, 2017.

[9] D. Chavez and F. Dove, "The Meaning, Relevance and Scope of Energy Democracy," 2015. [Online]. Available: https://www.tni.org/en/article/themeaningrelevance-and-scope-of-energy-democrac.

[10] M. Prebble and A. Rojas, "Energizing equality: The importance of intergrating gender equality principles in national energy policies and frameworks," IUCN Global Gender Office, Washington, 2017.

[11] J. K. Parikh, "Gender issues in energy policy," Energy Policy (23), pp. 745-754, 1995.

[12] UNDP, "Gender and Energy for Sustainable Development: A toolkit and resources guide," United Nations Development Program, New York, USA, 2004.

[13] R. Listo, "Gender myths in energy poverty literature: A critical Discourse Analysis," Energy Research \& Social Science 38, pp. 9-18, 2018.

[14] C. Ridgeway, Framed by gender. How gender inequality persists in the modern world., New York: Oxford University Press, 2011.

[15] E. Cecelski, "ENERGIA/Ease Discussion paper: Rethinking gender and energy: old and new directions," 2004.

[16] C. Fraune, "Gender matters: Women, renewable energy, and citizen partcipation in Germany," Energy Research \& Social Science 7 , pp. 55-65, 2015.

[17] N. Biggart and L. Lutzenhiser, "Economic sociology and the social problem of energy inefficiency," American Behavioral Scientist 50, pp. 1070-1087., 2007.

[18] J. Keirstead, "Evaluating the applicability of integrated domestic energy consumption frameworks in the UK," Energy Policy, pp. 3065-3077, 2006.

[19] R. Dholakia, N. Dholakia and A. Firat, "From social psychology to political economy: A model of energy use behavior," Journal of Economic Psychology 3, pp. 231247, 1983.

[20] W. Van Raaij and T. Verhallen, "A behavioral model of residential energy use," Journal of Economic Psychology 3, pp. 39-63, 1983.
[21] L. Lutzenhiser, "A cultural model of household energy consumption," Energy, pp. 47-60, 1992.

[22] R. Wilk, "Consumption, human needs, and global environmental change," Global Environmental Change 12, pp. 5-13, 2002.

[23] J. Keirstead, "Evaluating the applicability of integrated domestic energy consumption frameworks in the UK," Energy Policy 34, pp. 3065-3077, 2006.

[24] J. Angel, "Strategies of Energy Democracy," RosaLuxemburg-Stiftung, Brussels, Brussels, Belgium, 2016

[25] J. Markard, R. Raven and B. Truffer, "Sustainability transitions: an emerging field of research and its prospects," Res. Policy 41 (6), pp. 955-967, 2012.

[26] A. Giancatarino, "Community-Scale Energy: Models, Strategies and Racial Equity - A Scan of Community Innovation Around Efficiency and Renewable Energy," Center for Social Inclusion, New York, N.Y, 2013.

[27] G. Thompson and M. Bazilian, "Democratization, energy poverty, and the pursuit of symmetry," Global Policy 5 (1) , pp. 127-131, 2014.

[28] A. Weinrub and A. Giancatarino, "Toward a Climate Justice Energy Platform: Democratizing Our Energy Future," 208 2018. [Online]. Available: localcleanenergy.org.

[29] L. Mumford, "Power and Culture," in In Merrill, O (ed), Transactions: Third World Power Conference, Washington, 1938.

[30] R. Boyd and P. Richerson, "Voting with Your Feet: Payoff biased migration and the evolution of group beneficial behavior," J Theor Biol 257, pp. 331-339, 2009.

[31] D. McCort and N. Malhotra, "Culture and Consumer Behaviour: toward an understanding of cross-cultural consumer behaviour in international marketing," Journal of International Consumer Marketing, 62 (2) , pp. 91-127, 1993.

[32] M. Søndergaard, "Hofstede's consequences: A study of reviews,citations and replications," Organization Studies, 15 (3), pp. 447-453., 1994.

[33] G. Hofstede, Culture's Consequences: International differences in work-related values, Beverly Hills, CA: Sage, 1980.

[34] "Women's Empowerment Programme Nepal," 2009.

[35] B. Flyvbjerg, "Case study," in Qualitative Reseach, CA, Sage, 2011, pp. 301-316.

[36] WorldBank, "Nepal sytematic country diagonistic," World Bank, Washington, 2018.

[37] I. O. Adelekan and A. T. Jerome, "Dynamics of household energy conumption in a traditional African city, Ibadan," Environmnetalist, pp. 99-110, 2006. 
[38] B. Hou, H. Liao and J. Huang, "Household cooking fuel choice and economic poverty: Evidence from a nationwide survey in China," Energy \& Buildings 166, pp. 319-329, 2018

[39] WECS, Nepal Energy Outlook, 2014.

[40] M. O. Nepal, "Nepal Demographic and Health Survey," Rockville, University of Maryland, Maryland, 2016.

[41] P. O'Keefe, G. O 'Brien and N. Pearsall, The Future of Energy Use, UK, 2010.

[42] R. Sussman, "ACEE, How understanding the psychology of energy efficiency can help protect the environment?," 12 2016. [Online]. Available: http://aceee.org/blog/2016/12/how-understandingpsychology-energy. [Accessed 212 2017].

[43] V. Michelle; S. M Stonmen,., "Reaching the High Hanging Fruit Through Behaviour Change: How community based social marketing puts energy saving $\mathrm{s}$ within reach," 2011. 